\title{
Studies of the Culicoides \\ of Iran
}

\author{
by SHAHIN NAVAI
}

Department of Entomology, University of Maryland, College Park, Md. 20742, U.S.A.

\section{Summary:}

The author completes the study of the iranian Culicoides indicating the species now reported.

The seasonal distribution of Culicoides is also studied.

\section{Résumé.}

\section{Etude des Culicoides en Iran.}

L'auteur complète l'étude des Culicoïdes d'Iran en indiquant les espèces actuellement répertoriées.

La distribution saisonnière des Culicoïdes est également étudiée.

Horse-sickness appeared in Iran in epidemic form in 1959-1960 and spread rapidly in the most part of the East from Kerman up to the Northern border, Turkmanistan. After the appearance of this serious disease, the study of Culicoides was necessary. The first report was given by Mesghali, 1963.

This report contains the results of the study carried out by A. Mesghali and the author.

Species of the genus Culicoides are widely distributed over the country. We in our studies only collected from a few areas in the country (fig. 1) and not in all landszape-climatic zones. We did some study in desert climate, Ab-Shirinak, but not any study was done in forest areas.

Forty-three species of Culicoides were recorded from Iran. To compare this number with 65 species recorded from Transcaucasia (Dzhafarov, 1964), the neigh- 
bour country in the north, shows still we have many undescribed species. A complete survey needed to be done in different parts of the country in order to know the local species.

In all investigations the adult insects were collected by New Jersey light traps and sticky papers.

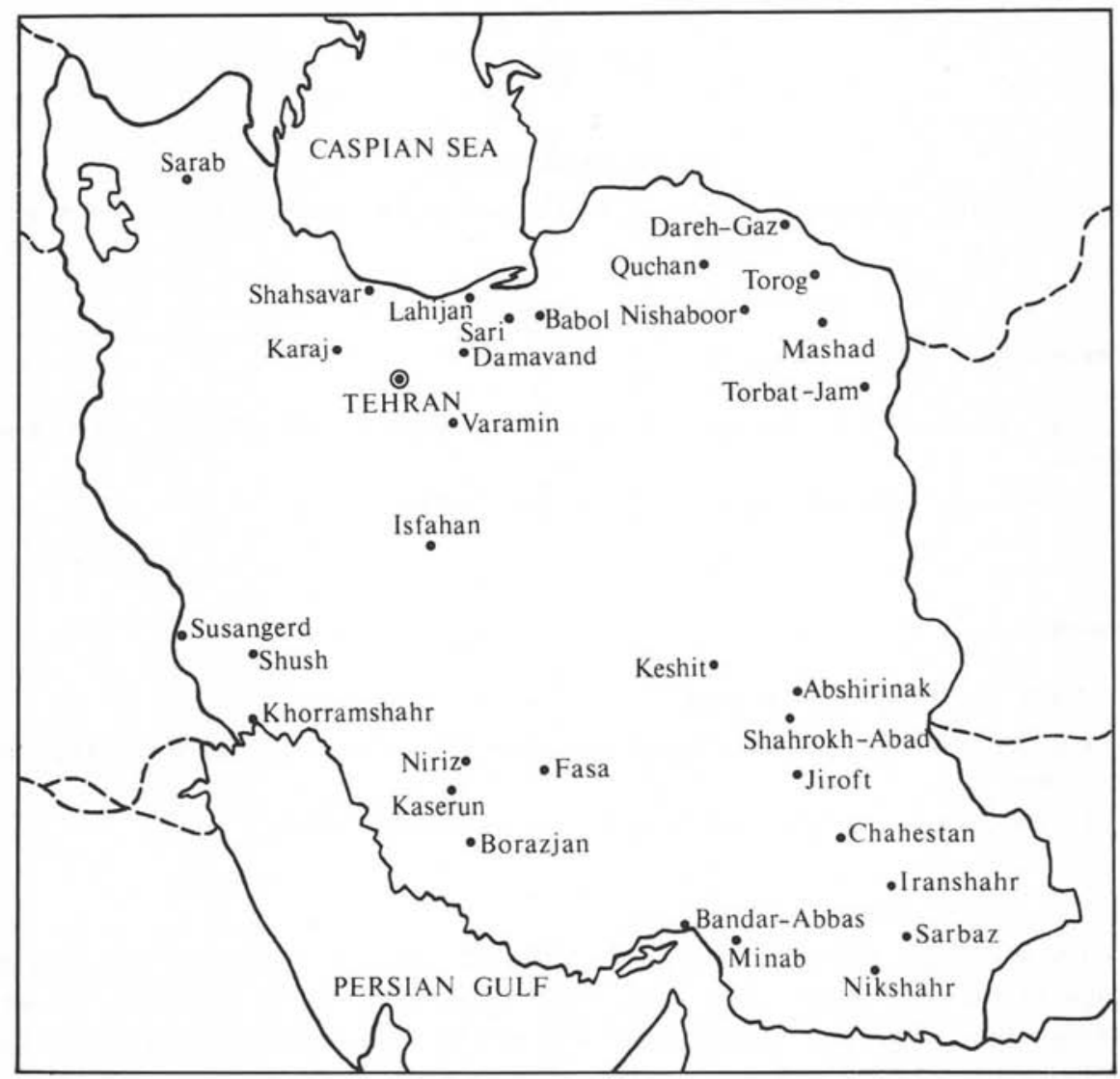

FIG. 1. - Location of the Culicoides collection sites in Iran

The following species were collected and identified from 1961-1970: C. azerbajdzhanicus, C. bulbostylus, C. caspius, C. circumscriptus, C. dendrophilus, C. dzhafavori, C. faghihi, C. flavidus, C. flavisimilis, C. grisescens, C. halophilus, C. firuzeri, C. heliophilus, C. ibericus, C. iranica, C. korensis, C. kurensis, C. lailae, C. langeroni, C. maritimus, C. mesghalii, C. mosulensis, C. nagahanai, C. odibilis, C. omogensis, C. pallidicornis, C. pallidipennis, C. pallidus, C. parroti, C. pictimargo, $C$. 
pictipennis, C. pulicaris, C. puncticollis, C. riethi, C. saevus, C. schultzei, C. sejfadinei, C. semimaculatus, C. shahgudiani, C. similis, C. similisbaghdadensis, C. simulator, C. subfascipennis.

The seasonal distributions were done in two collection sites:

1. at Chahar-Dongeh, Karaj (in north) during 1964-1965 (Navai, 1965),

2. at Zyarat-Ali, Bandar-Abbas (in south) during 1968-1969 (unpublished data).

At Chahar-Dongeh the first flying adult (1 female, $C$. puncticollis) appeared on April 15 (fig. 2) and continued until October 19 (1 female, 1 male. C. heliophilus $\left.{ }^{1}\right)$. The most abundant species at Chahar-Dangeh is $C$. puncticollis. It was found that the adult of $C$. puncticollis at Chahar-Dangeh increased to maximum numbers during the last week of May.

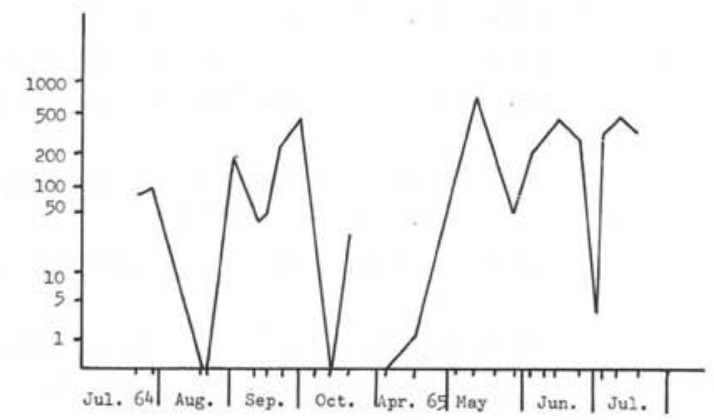

FIG. 2. - Seasonal distribution of male and female C. puncticollis in 1964-1965 at ChaharDangeh, Karaj, per light trap.

At Zyarat-Ali, Bandar-Abbas, the first flying adult appeared on March 15 (1 male, C. langeroni, 1 female, C. mosulensis) and continued until December 19 (1 female, C. pulicaris, 1 female, C. semimaculatus and 1 female, $C$. mosulensis). From December 20, 1968 to January 18, 1969 the collection was not possible due to erosion after rain covering the roads. However, the 19 of December cannot be considered as the last day of flying adults. Adults might fly during the late December to the middle of January.

The most abundant species at Zyarat-Ali, Bandar-Abbas is C. mosulensis. This species at Zyarat-Ali reached to the maximum number in the middle of July.

The adult-flying Culicoides are absent at Zyarat-Ali about 3 months or less in a year. They are absent at Chahar-Dongeh for more than 5 months in a year.

A revision needs to be done in our collection in order to correct some misiden-

(1) This sepcies was identified later as $C$. dzhafarovi. 
tified specimens. Some species like $C$. caspius, $C$. similis, $C$. dendrophilus, $C$. parroti have been recorded with one or two specimens and are not present in the collection.

Since the spermatheca of $C$. puncticollis is very variable in form and also there is no reliable difference in the structure of male genitalia of $C$. puncticollis and C. riethi, I believe these two species are the same and the earlier name «puncticollis» should be used, unless some immature stage studies or biological studies prove the differences between the two species.

\section{Bibliographie}

Dzhafarov (Sh. M.), 1964. - The biting midges (Diptera, Heleidae) of Transcaucasia, Baku, 414 p.

Mesghali (A.), 1963. - Heleidae Diptera of Iran. I. Some record of midges of the Culicoides. Bull. Soc. Path. Exot., 56 (5), 1063-1069.

NavaI (Sh.), 1965. - Study of the Culicoides (Diptera, Ceratopogonidae) of Chahar-Dangeh, Karaj. Faculty of Science, Univ. of Tehran, Tehran, Iran. Thesis to receive the M. Sc. degree, $107 \mathrm{p}$.

- and Mesghali (A.), 1968. - Ceratopogonidae (Diptera) of Iran. II. More records of Culicoides Latreille, 1809. J. Nat. Hist., 2, 241-246.

-, 1970. - Ceratopogonidae (Diptera) of Iran. V. Culicoides from Mazandaran. Mosquito News, 30 (1), 6-8.

-, 1971. - Culicoides from Southern part of Lut Desert, Iran, with two new species (Diptera: Ceratopogonidae). Mosquito News, 31 (2), 199-206. 